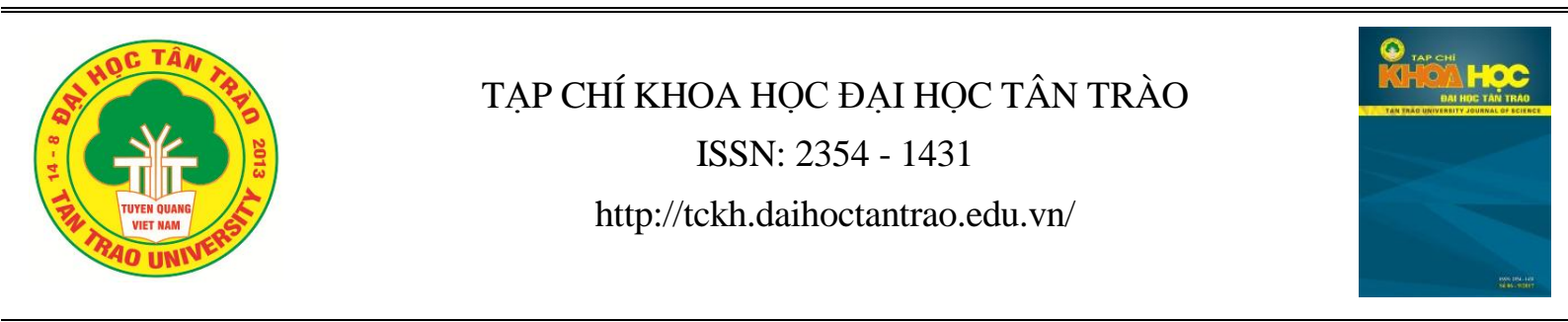

\title{
NGHIÊN CỨU HIỆN TRẠNG SỦ DỤNG ĐÂT VÀ CÔNG TÁC QUẢN LÝ, ĐO ĐẠC BẢN ĐỒ ĐỊA CHÍNH TRÊN ĐỊA BÀN TỈNH THÁI NGUYÊN
}

\author{
Trần Thị Thu Hiền ${ }^{1 *}$, Lê Thị Thu ${ }^{l}$, Đàm Thị Thanh Thủy ${ }^{2}$ \\ ITruờng Cao đẳng Kinh tế - Kỹ Thuật, Đại học Thái Nguyên \\ 2 Đại học Tân Trào \\ *Email:Thuhiencdkt2@gm
}

\section{Thông tin bài viết}

Ngày nhận bài:

11/7/2020

Ngày duyệt đăng:

$12 / 8 / 2020$

Tù khóa:

Nghiên cứu; hiên trang;sử dụng đất;quản lý; đo đạc; bản đồ địa chính; Thái Nguyên.

\section{Tóm tắt}

Trong những năm gần đây, tỉnh Thái Nguyên có tốc độ đô thị hóa nhanh, nên công tác quản lý đo đạc và thành lập bản đồ địa chính nhằm quản lý và sử dụng một cách hợp lý, có hiệu quả nhất công tác quản lý nhà nước về đất đai là hết sức cần thiết. Bản đồ địa chính tỉnh Thái Nguyên được thành lập trong hơn 30 năm qua (từ năm 1986 đến nay) bằng công nghệ truyền thống và công nghệ số nên có sự khác biệt về độ chính xác. Các địa phương đo đạc trước năm 2000 bằng công nghệ truyền thống, đo bằng máy kinh vĩ quang cơ, xử lý số liệu, biên tập bản đồ, tính toán diện tích bằng phương pháp thủ công, nên bản đồ có chất lượng hạn chế, độ chính xác thấp, dẫn đến khó khăn cho công tác quản lý đất đai bằng công nghệ thông tin theo hướng hiện đại. Tính đến ngày 31/12/2019 tỉnh Thái Nguyên đã tổ chức thực hiện công tác đo đạc lập bản đồ địa chính cho 180/180 xã, phường, thị trấn thuộc 9 huyện, thành phố, thị xã, khối lượng đã hoàn thành cụ thể như sau: Khối lượng lập lưới địa chính là 979 điểm tại thành phố Thái Nguyên, thành phố Sông Công, huyện Đồng Hỷ, huyện Định Hóa, huyện Võ Nhai, huyện Phú Lương và huyện Đại Từ. Tổng diện tích đã đo đạc lập bản đồ địa chính 340.945,7 ha/352.664 ha, chiếm 96,7\% tổng diện tích tự nhiên toàn tỉnh.

\section{1. ĐẠT VẤN ĐỀ}

Tỉnh Thái Nguyên là trung tâm chính trị, kinh tế của khu Việt Bắc nói riêng, của vùng trung du miền núi đông bắc nói chung, là cửa ngõ giao lưu kinh tế xã hội giữa vùng trung du miền núi với vùng đồng bằng Bắc Bộ.

Phần lớn bản đồ địa chính trên địa bàn các huyện, thị xã, thành phố thuộc tỉnh trước kia được đo đạc theo hệ tọa Nhà nước $\mathrm{HN} 72$ bằng công nghệ truyền thống có độ chính xác hạn chế, sau đó được số hóa, chuyển đổi về hệ tọa độ Quốc gia VN2000. Bản đồ địa chính có vai trò quan trọng trong công tác quản lý nhà nước về đất đai. Tuy nhiên, sau nhiều năm đến nay đất đai có biến động lớn nhưng việc chỉnh lý bản đồ chưa được đầy đủ, kịp thời, thiếu đồng bộ, độ chính xác không đảm bảo quy định. Việc sử dụng bản đồ gặp nhiều khó khăn, không đáp ứng được yêu cầu quản lý đất đai trong thời kỳ mới.
Sở Tài nguyên và Môi trường Thái nguyên đã tổ chức triển khai thực hiện thiết kế kỹ thuật - Dự toán được UBND tỉnh phê duyệt, với các hạng mục công việc bao gồm đo đạc chỉnh lý bản đồ địa chính bằng công nghệ số có độ chính xác cao theo hệ tọa độ quốc gia VN2000, thay thế hệ thống bản đồ công nghệ truyền thống hệ tọa độ HN72 trước đây, trên cơ sở đó thực hiện công tác đăng ký đất đai, cấp mới và cấp đổi GCNQSD đất, lập hồ sơ địa chính làm cơ sở để xây dựng hoàn thiện cơ sở dữ liệu địa chính nhằm đáp ứng tốt yêu cầu của công tác quản lý nhà nước về đất đai theo luật đất đai 2013 theo chủ trương của Bộ Tài nguyên và môi trường. Hệ thống bản đồ địa chính, hồ sơ địa chính và cơ sở dữ liệu địa chính đã xây dựng góp phần đắc lực trong việc nâng cao chất lượng, hiệu quả công tác quản lý nhà nước về đất đai của các cấp [4]. 


\section{NỘI DUNG VÀ PHƯƠNG PHÁP NGHIÊN CÚU}

\section{1. Đối tượng, thời gian nghiên cứu}

2.1.1. Đối tượng nghiên cưu

Nghiên cứu hiện trạng sử dụng đất và công tác quản lý, đo đạc bản đồ địa chính trên địa bàn tỉnh Thái Nguyên.

\subsubsection{Thời gian nghiêncưu}

Từ năm 2018 đến năm 2020

\subsection{Nội dung nghiên cứu}

(i) Khái quát về điều kiện tự nhiên, kinh tế và xã hội của tỉnh Thái Nguyên

(ii) Hiện trạng sử dụng đất tỉnh Thái Nguyên.

(iii) Nghiên cứu công tác quản lý, đo đạc bản đồ địa chính trên địa bàn tỉnh Thái Nguyên

\subsection{Phương pháp nghiên cứu}

Phuoong pháp thu thập tài liệu

Các tài liệu được thu thập cả 3 cấp: Trung tâm Công nghệ thông tin - Sở Tài nguyên và Môi trường tỉnh Thái Nguyên, Văn phòng Đăng ký đất đai tỉnh Thái Nguyên, Phòng TNMT, Chi nhánh Văn phòng Đăng ký đất đai, Ủy ban nhân dân các phường, xã. Gồm những tài liệu sau:

Bản đồ địa chính hệ HN72; Bản đồ chỉnh lý; Bản trích đo các thửa đất theo chỉ thị số: 31-CTTTg năm 2008; Bản đồ đo vẽ theo chỉ thị số: 31CT-TTg năm 2008; Bản đồ hiện trạng sử dụng đất; Các bản trích đo, trích lục đất tổ chức; Các điểm tọa độ địa chính cơ sở, điểm tọa độ địa chính; Sổ địa chính, sổ mục kê đất đai, sổ cấp giấy chứng nhận quyền sử dụng đất, sổ đăng ký biến động đất đai; Giấy chứng nhận QSD đất đã cấp từ trước tới nay;

Phuơng pháp đo vẽ chi tiết, chỉnh lý bản đồ địa chính

- Xác định địa giới hành chính trên cơ sở hồ sơ địa giới và thực tế sử dụng đất.

- Đối soát thực địa, xác định khu vực đo đạc chỉnh lý bản đồ địa chính.

- Trên cơ sở hệ thống điểm lưới địa chính đã có trên địa bàn tiến hành thiết kế và thành lập lưới khống chế đo vẽ phủ trùm đảm bảo đủ mật độ điểm để đo vẽ thành lập bản đồ địa chính.

- Xác định ranh giới mốc giới thửa đất, lập bản mô tả ranh giới mốc giới thửa đất:

+ Xác định và đánh dấu ranh giới các thửa đất tại thực địa. Lập bản mô tả ranh giới, mốc giới thửa đất, giao cho các chủ sử dụng đất liên quan và người dẫn đạc ký xác nhận.
+ Trường hợp các thửa đất có tranh chấp thì UBND phường, xã có trách nhiệm giải quyết và ra quyết định bằng văn bản để có căn cứ thực hiện.

+ Thu thập thông tin về hồ sơ pháp lý, mục đích đang sử dụng đất, người sử dụng đất; nguồn gốc sử dụng đất; tình trạng tranh chấp sử dụng đất; tình hình biến động ranh giới, diện tích thửa đất so với giấy tờ về quyền sử dụng đất.

- Công tác đo vẽ chi tiết nội dung bản đồ:

+ Bản đồ địa chính được thành lập bằng phương pháp đo vẽ trực tiếp ngoài thực địa, sử dụng máy toàn đạc điện tử đo vẽ đất khu dân cư (Đo theo phương pháp toàn đạc) và công nghệ GNSS đo vẽ đất nông nghiệp (Phương pháp đo động thời gian thực RTK).

+ Đo đạc chi tiết ranh giới thửa đất theo ranh giới thửa đất đã được thống nhất tại thực địa, lập bản mô tả ranh giới, mốc giới thửa đất và các nội dung khác. Chỉnh lý, cập nhật từ hồ sơ pháp lý, biên tập hoàn chỉnh bản đồ.

+ Trong quá trình đo đạc sẽ tiến hành đồng thời việc thu thập các thông tin về thửa đất như: tên chủ sử dụng, tên xứ đồng, địa danh, tên sông suối, loại đất và các thông tin địa chính khác của thửa đất

\section{Phuoong pháp biên tập bản đồ địa chính}

- Tiếp biên bản đồ, biên tập thành lập bản đồ địa chính:

+ Bản đồ địa chính sau khi đo vẽ phải được tiếp biên giữa các mảnh với nhau, với các đơn vị hành chính liền kề để đảm bảo đo hết diện tích, không trùng, hở diện tích.

+ Kết hợp với địa chính xã, phường, cùng các tổ trưởng tổ dân phố kiểm tra rà soát nhằm tìm ra các thửa đất công, các thửa đất $5 \%$ của địa phương nhằm tránh tình trạng cấp giấy chứng nhận chồng lấn lên các thửa đất này.

+ Lập bảng tổng hợp số thửa, số chủ sử dụng, diện tích từng mảnh bản đồ theo đơn vị hành chính phường, xã lập bảng thống kê diện tích đất theo hiện trạng đo đạc và xác nhận diện tích tự nhiên [1].

\section{KÊTT QUẢ NGHIÊN CÚU VÀ THẢO LUẬN}

3.1. Khái quát về điều kiện tự nhiên, kinh tế và xã hội của tỉnh Thái Nguyên

\section{Đặc điểm địa hình}

Thái Nguyên có nhiều dãy núi cao chạy theo hướng Bắc Nam và thấp dần xuống phía Nam. Cấu trúc vùng núi phía Bắc chủ yếu là đá phong hóa mạnh, tạo thành nhiều hang động và thung lũng 
nhỏ. Phía Tây Nam có dãy Tam Đảo với đỉnh cao nhất $1.590 \mathrm{~m}$, các vách núi dựng đứng và kéo dài theo hướng Tây Bắc - Đông Nam. Ngoài dãy núi trên còn có dãy Ngân sơn bắt đầu từ Bắc Kạn chạy theo hướng Đông Bắc, Tây Nam đến Võ Nhai và dãy núi Bắc Sơn chạy theo hướng Tây Bắc, Đông Nam. Cả ba dãy núi Tam Đảo, Ngân Sơn, Bắc Sơn đều là những dãy núi cao che chắn gió mùa đông bắc.

Khì hậu

Do nằm sát chí tuyến Bắc trong vành đai Bắc bán cầu, nên khí hậu của tỉnh Thái Nguyên mang tính chất của nhiệt đới gió mùa. Trên địa bàn tỉnh Thái Nguyên vào mùa nóng từ tháng 5 đến tháng 10, nhiệt độ trung bình khoảng 23 - 28.

Tình hình giao thông vận tải

Thái Nguyên hiện có 3 tuyến quốc lộ đi qua là Quốc lộ 3, quốc lộ $1 \mathrm{~B}$, quốc lộ 37; tuyến đường cao tốc Thái Nguyên - Hà Nội: tuyến đường sắt Hà Nội
- Quán Triều. Bao quanh các phường, xã là các trục đường nhựa và đường bê tông.

Đặc điểm phân bố dân cur

Dân số trung bình năm 2019 trên địa bàn là 1.255 nghìn người; tăng 11,3 nghìn người so với năm 2018. Dân số khu vực thành thị chiếm $35,1 \%$ và dân số khu vực nông thôn chiếm $64,9 \%$ tổng dân số.

Nhìn chung điều kiện tự nhiên, kinh tế, xã hội của tỉnh Thái nguyên tương đối thuận lợi cho công tác đo đạc thành lập, bổ sung, chỉnh lý bản đồ địa chính. Tuy nhiên, Thái nguyên là tỉnh miền núi, các yếu tố địạ hình tương đối phức tạp nhiều đồi núi đây cũng là yếu tố ảnh hưởng đến công tác đo đạc thành lập, bổ sung, chỉnh lý bản đồ địa chính.

\subsection{Hiện trạng sử dụng đất tỉnh Thái Nguyên}

Theo kết quả tổng kiểm kê đất đai tính đến ngày 31/12/2019 diện tích tự nhiên của tỉnh Thái Nguyên là 352.664 ha, phân theo mục đích sử dụng như sau:

Bảng 1. Hiện trạng sử dụng đất tỉnh Thái Nguyên năm 2019

\begin{tabular}{|c|c|c|c|c|}
\hline STT & Chỉ tiêu & Mã & $\begin{array}{l}\text { Diện tích } \\
\text { (ha) }\end{array}$ & $\begin{array}{c}\text { Co cấu } \\
(\%)\end{array}$ \\
\hline $\mathbf{I}$ & TỔNG DIỆN TÍCH TỰ NHIÊN & & 352.664 & 100,0 \\
\hline 1 & Đất nông nghiệp & NNP & 303.555 & 86,08 \\
\hline 1.1 & Đất sản xuất nông nghiệp & $S X N$ & 112.048 & 31,77 \\
\hline 1.1 .1 & Đất trồng cây hàng năm & $\mathrm{CHN}$ & 61.029 & 17,31 \\
\hline 1.1.1.1 & Đất trồng lúa & LUA & 44.754 & 12,69 \\
\hline 1.1 .1 .2 & Đất trồng cây hàng năm khác & HNK & 16.275 & 4,61 \\
\hline 1.1 .2 & Đất tồng cây lâu năm & CLN & 51.019 & 14,47 \\
\hline 1.2 & Đất lâm nghiệp & $L N P$ & 186.648 & 52,92 \\
\hline 1.2 .1 & Đất rừng sản xuất & RSX & 109.605 & 31,09 \\
\hline 1.2 .2 & Đất rừng phòng hộ & RPH & 37.688 & 33,10 \\
\hline 1.2 .3 & Đất rừng đặc dụng & RDD & 39.354 & 10,69 \\
\hline 1.3 & Đất nuôi trồng thủy sản & NTS & 4.622 & 1,31 \\
\hline 1.4 & Đất nông nghiệp khác & $N K H$ & 237 & 0,07 \\
\hline 2 & Đất phi nông nghiệp & PNN & 44.445 & 12,63 \\
\hline 2.1 & Đất ở & OCT & 12.346 & 4,06 \\
\hline 2.1 .1 & Đất ở tại nông thôn & ONT & 9.834 & 2,78 \\
\hline 2.1 .2 & Đất ở tại đô thị & ODT & 2.512 & 0,71 \\
\hline 2.2 & Đất chuyên dùng & CDG & 21.760 & 6,17 \\
\hline 2.2 .1 & Đất xây dựng trụ sở cơ quan & TSC & 158 & 0,04 \\
\hline 2.2 .2 & Đất quốc phòng & CQP & 2.657 & 0,75 \\
\hline 2.2 .3 & Đất an ninh & CAN & 479 & 0,14 \\
\hline 2.2 .4 & Đất xây dựng công trình sự nghiệp & DSN & 1.269 & 0,36 \\
\hline
\end{tabular}




\begin{tabular}{|c|c|c|c|c|}
\hline STT & Chỉ tiêu & Mã & $\begin{array}{c}\text { Diện tích } \\
\text { (ha) }\end{array}$ & $\begin{array}{c}\text { Co cấu } \\
(\%)\end{array}$ \\
\hline 2.2 .5 & Đất sản xuất, kinh doanh phi NN & CSK & 5.157 & 1,46 \\
\hline 2.2 .6 & Đất có mục đích công cộng & $\mathrm{CCC}$ & 12.041 & 3,41 \\
\hline 2.3 & Đất cơ sở tôn giáo & TON & 81 & 0,02 \\
\hline 2.4 & Đất cơ sở tín nguõ̃ng & TIN & 69 & 0,02 \\
\hline 2.5 & Đất làm nghĩa trang, nghĩa địa... & NTD & 837 & 0,24 \\
\hline 2.6 & Đất sông, ngòi, kênh, rạch, suối & SON & 5.642 & 1,60 \\
\hline 2.7 & Đất có mặt nước chuyên dùng & MNC & 3.698 & 1,05 \\
\hline 2.8 & Đất phi nông nghiệp khác & PNK & 12 & 0,003 \\
\hline 3 & Đất chưa sử dụng & CSD & 4.664 & 1,33 \\
\hline 3.1 & Đất bằng chưa sử dụng & BCS & 989 & 0,28 \\
\hline 3.2 & Đất đồi núi chưa sử dụng & DCS & 1.517 & 0,43 \\
\hline 3.3 & Núi đá không có rừng cây & NCS & 2.157 & 0,61 \\
\hline
\end{tabular}

(Nguồn số liệu: Sở Tài nguyên và Môi truờng tỉnh Thái Nguyên, 2019)[2]

* Đất nông nghiệp: Là 303.555 ha, chiếm 86,08\% tổng diện tích tự nhiên, trong đó:

- Diện tích đất sản xuất nông nghiệp là 112.048 ha, chiếm $31,77 \%$.

- Diện tích đất trồng cây lâu năm là 51.019 ha, chiếm $14,57 \%$

- Diện tích đất trồng cây hàng năm là 61.029 ha, chiếm $17,31 \%$.

* Đất phi nông nghiệp: Là 44.445 ha, chiếm 12,63\% tổng diện tích đất tự nhiên, trong đó:

- Diện tích đất ở là 12.346 ha, chiếm 4,06\%

- Diện tích đất chuyên dùng là 21.760 ha, chiếm $6,17 \%$.

* Diện tích đất chưa sử dụng: Là 4.664 ha, chiếm 1,33\% tổng diện tích đất tự nhiên.

Trong cơ cấu các loại đất, đất nông nghiệp có tỷ trọng cao và có xu hướng giảm dần do quá trình đô thị hoá. Tỷ trọng đất phi nông nghiệp có xu hướng tăng, với tốc độ gia tăng dân số như hiện nay thì trong tương lai quỹ đất ở của tỉnh sẽ còn mở rộng.

3.3. Nghiên cứu công tác quản lý, đo đạc bản đồ địa chính trên địa bàn tỉnh Thái Nguyên

3.3.1. Kết quả đo đạc bản đồ địa chính của tỉnh Thái Nguyên

Tính đến hết năm 2019 tỉnh Thái Nguyên đã thực hiện đo đạc lập bản đồ địa chính được 180/180 xã, phường, thị trấn thuộc 9 huyện, thành phố, thị xã với tổng diện tích là 340.945,7 ha/352.664 ha, chiếm 96,7\% tổng diện tích tự nhiên toàn tỉnh.
Công tác đo đạc thành lập, bổ sung, chỉnh lý bản đồ địa chính trong những năm qua đã đạt được những kết quả quan trọng, là cơ sở để thực hiện công tác đăng ký, cấp GCNQSD đất, lập, hoàn thiện hồ sơ địa chính và xây dựng CSDL địa chính trên địa bàn tỉnh. Hệ thống bản đồ địa chính, hồ sơ địa chính và cơ sở dữ liệu địa chính đã xây dựng góp phần đắc lực trong việc nâng cao chất lượng, hiệu quả công tác quản lý nhà nước về đất đai của các cấp.

Hệ thống bản đồ địa chính đã thành lập có ý nghĩa, vai trò hết sức quan trọng, là cơ sở để xây dựng hoàn thiện hệ thống hồ sơ địa chính và cơ sở dữ liệu địa chính ở các địa phương phục vụ công tác quản lý nhà nước về đất đai của các cấp. Bản đồ được thành lập bằng công nghệ số, sử dụng các thiết bị công nghệ đo đạc có độ chính xác cao, thống nhất về cơ sở toán học, cùng với các tài liệu kèm theo bản đồ được lập đầy đủ, đồng bộ, đáp ứng ngày càng tốt hơn yêu cầu quản lý nhà nước về đất đai trong thời kỳ mới. Đặc biệt là các địa phương có bản đồ công nghệ truyền thống thành lập trước năm 2000, đến nay đã được đo đạc chỉnh lý bằng công nghệ số nâng cao chất lượng và độ chính xác thay thế cho bản đồ cũ, tạo điều kiện thuận lợi để thực hiện công tác đăng ký đất đai, cấp đổi GCNQSD đất, xây dựng hoàn thiện hệ thống hồ sơ địa chính và cơ sở dữ liệu địa chính, đáp ứng tốt yêu cầu quản lý, góp phần tăng cường hiệu lực, hiệu quả của công tác quản lý nhà nước về đất đai trên địa bàn tỉnh. 
T.T.T.Hien et al/No.17_Aug 2020|p.96-102

Bảng 2: Kết quả đo đạc bản đồ địa chính tính đến 30/12/2019

\begin{tabular}{|c|c|c|c|c|c|c|c|c|c|}
\hline \multirow{2}{*}{ TT } & \multirow{2}{*}{$\begin{array}{c}\text { Tên đơn vị } \\
\text { hành chính cấp } \\
\text { huyện }\end{array}$} & \multirow{2}{*}{$\begin{array}{l}\text { Diện } \\
\text { tích tự } \\
\text { nhiên } \\
\text { (ha) }\end{array}$} & \multirow{2}{*}{$\begin{array}{l}\text { Tổng } \\
\text { diện } \\
\text { tích đã } \\
\text { đo đạc } \\
\text { (ha) }\end{array}$} & \multicolumn{5}{|c|}{ Trong đó } & \multirow{2}{*}{$\begin{array}{c}\text { Số thửa } \\
\text { đã đo } \\
\text { đạc lập } \\
\text { bản đồ } \\
\text { địa } \\
\text { chính } \\
\text { (thửa) }\end{array}$} \\
\hline & & & & $\begin{array}{l}\text { Tỷ lệ } \\
\text { 1/500 }\end{array}$ & $\begin{array}{c}\text { Tỷ lệ } \\
\text { 1/1000 }\end{array}$ & $\begin{array}{c}\text { Tỷ lệ } \\
\text { 1/2000 }\end{array}$ & $\begin{array}{c}\text { Tỷ lệ } \\
\text { 1/5000 }\end{array}$ & $\begin{array}{c}\text { Tỷ lệ } \\
\text { 1/10000 }\end{array}$ & \\
\hline & Tổng số & 352.664 & $340.945,7$ & $1.414,9$ & $94.595,4$ & $88.454,9$ & $67.247,7$ & 89.232,8 & 2.657.037 \\
\hline 1 & $\begin{array}{l}\text { Huyện Định } \\
\text { Hoá }\end{array}$ & 51.352 & $51.352,0$ & & $11.779,3$ & $6.965,0$ & $10.791,8$ & $21.815,9$ & 282.352 \\
\hline 2 & $\begin{array}{l}\text { TP. Thái } \\
\text { Nguyên }\end{array}$ & 22.293 & $22.293,0$ & $1.202,7$ & $6.947,6$ & $11.343,7$ & $2.799,0$ & & 375.319 \\
\hline 3 & TX. Phổ Yên & 25.889 & $21.058,5$ & 84,3 & $6.406,8$ & $11.795,6$ & $2.771,8$ & & 348.811 \\
\hline 4 & TP. Sông Công & 9.671 & $8.384,2$ & & $6.822,6$ & $1.561,6$ & & & 68.886 \\
\hline 5 & Huyện Phú Bình & 24.337 & $21.074,8$ & & $1.712,5$ & $16.371,2$ & $2.991,1$ & & 399.306 \\
\hline 6 & Huyện Võ Nhai & 83.943 & $82.194,5$ & 53,6 & $8.087,6$ & $12.232,1$ & $2.275,6$ & $59.545,6$ & 139.352 \\
\hline 7 & Huyện Đồng Hỷ & 42.773 & $42.771,9$ & 74,3 & $13.425,0$ & $8.660,8$ & $15.171,2$ & $5.440,6$ & 230.052 \\
\hline 8 & $\begin{array}{l}\text { Huyện Phú } \\
\text { Lương }\end{array}$ & 35.071 & $34.925,7$ & & $10.860,7$ & $14.555,0$ & $9.510,0$ & & 281.152 \\
\hline 9 & Huyện Đại Từ & 57.335 & $56.891,1$ & & $28.553,3$ & $4.969,9$ & $20.937,2$ & $2.430,7$ & 531.807 \\
\hline
\end{tabular}

(Nguồn số liệu: Sở Tài nguyên và Môi trương tỉnh Thái Nguyên, 2019)[3]

3.3.2. Quản lý bản đồ địa chính

Bảng 3: Số lượng bản đồ địa chính đã được thành lập

trên địa bàn tỉnh Thái Nguyên đến tháng 6 năm 2019

\begin{tabular}{|c|l|c|c|c|c|c|c|}
\hline \multirow{2}{*}{ STT } & \multirow{2}{*}{ Tên đơn vị hành chính } & \multicolumn{5}{|c|}{ Bản đồ địa chính (tờ bản đồ) } & \multirow{2}{*}{ Năm đo vẽ } \\
\cline { 3 - 7 } & & $\begin{array}{c}\text { Tỷ lệ } \\
\mathbf{1 / 5 0 0}\end{array}$ & $\begin{array}{c}\text { Tỷ lệ } \\
\mathbf{1 / 1 0 0 0}\end{array}$ & $\begin{array}{c}\text { Tỷ lệ } \\
\mathbf{1 / 2 0 0 0}\end{array}$ & $\begin{array}{c}\text { Tỷ lệ } \\
\mathbf{1 / 5 0 0 0}\end{array}$ & $\begin{array}{c}\text { Tỷ lệ } \\
\mathbf{1 / 1 0 0 0 0}\end{array}$ & \\
\hline 1 & TP. Thái Nguyên & 241 & 695 & 329 & 5 & & $1991-2015$ \\
\hline 2 & TX. Phổ Yên & 17 & 427 & 198 & 6 & & $1989-1993$ \\
\hline 3 & TP. Sông Công & & 401 & 57 & & & $1986-1987$ \\
\hline 4 & Huyện Phú Bình & & 171 & 340 & & & $1993-1994$ \\
\hline 5 & Huyện Võ Nhai & 11 & 809 & 509 & 11 & 34 & $1999-2015$ \\
\hline 6 & Huyện Đồng Hỷ & 15 & 895 & 328 & 39 & 3 & $1995-2015$ \\
\hline 7 & Huyện Phú Lương & & 724 & 318 & 19 & & $1998-2018$ \\
\hline
\end{tabular}




\begin{tabular}{|c|l|c|c|c|c|c|c|}
\hline \multirow{2}{*}{ STT } & \multirow{2}{*}{ Tên đơn vị hành chính } & \multicolumn{5}{|c|}{ Bản đồ địa chính (tờ bản đồ) } & \multirow{2}{*}{ Năm đo vẽ } \\
\cline { 3 - 7 } & & $\begin{array}{c}\text { Tỷ lệ } \\
\mathbf{1 / 5 0 0}\end{array}$ & $\begin{array}{c}\text { Tỷ lệ } \\
\mathbf{1 / 1 0 0 0}\end{array}$ & $\begin{array}{c}\text { Tỷ lệ̣ } \\
\mathbf{1 / 2 0 0 0}\end{array}$ & $\begin{array}{c}\text { Tỷ lệ } \\
\mathbf{1 / 5 0 0 0}\end{array}$ & $\begin{array}{c}\text { Tỷ lệ } \\
\mathbf{1 / 1 0 0 0 0}\end{array}$ & \\
\hline 8 & Huyện Đại Từ & & 1,428 & 432 & 28 & 20 & $1996-2016$ \\
\hline 9 & Huyện Định Hoá & & 1,178 & 490 & 23 & 14 & $1998-2019$ \\
\hline \multicolumn{2}{|c|}{ Tổng cộng } & $\mathbf{2 8 4}$ & $\mathbf{6 7 2 8}$ & $\mathbf{3 0 0 1}$ & $\mathbf{1 3 1}$ & $\mathbf{7 1}$ & \\
\hline
\end{tabular}

(Nguồn số liệu: Sở Tài nguyên và Môi truờng tỉnh Thái Nguyên, 2019)[5]

Bản đồ địa chính sau khi đo vẽ được bàn giao cho các cấp quản lý và sử dụng. Đối với các bản đồ được thành lập theo hệ tọa độ HN-72 đã được số hóa và chuyển hệ về hệ tọa độ quốc gia VN-2000, được lưu trữ và quản lý tại Trung tâm Công nghệ Thông tin và Văn phòng Đăng ký đất đai của Sở Tài Nguyên và Môi trường. Các bản đồ dạng giấy được phân loại, sắp xếp khoa học để sử dụng và lưu trữ tại 3 cấp gồm: Văn phòng Đăng ký đất đai của Sở Tài Nguyên và Môi trường (cấp tỉnh), Phòng Tài nguyên và Môi trường các huyện, thành phố, thị xã (cấp huyện), UBND các xã, phường, thị trấn (cấp xã). Việc sử dụng, bảo quản và cung cấp thông tin dữ liệu được thực hiện theo các quy định của pháp luật.

Công tác đo đạc thành lập, bổ sung, chỉnh lý bản đồ địa chính trong những năm qua đã đạt được những kết quả quan trọng, là cơ sở để thực hiện công tác đăng ký, cấp GCNQSD đất, lập, hoàn thiện hồ sơ địa chính và xây dựng CSDL địa chính trên địa bàn tỉnh cụ thể:

- Đo đạc thành lập bản đồ địa chính gắn với cấp GCNQSD đất và xây dựng cơ sở dữ liệu địa chính tại 28 xã, thị trấn thuộc 4 huyện Võ Nhai, Đồng Hỷ, Định Hoá, Đại Từ với tổng diện tích 21.291,0 ha;

- Đo đạc bổ sung bản đồ địa chính tại 25 xã, phường, thị trấn thuộc 5 đơn vị cấp huyện (TP Thái Nguyên, các huyện Phú Bình, Đồng Hỷ, Phú Lương và thị xã Phổ Yên);

- Đo đạc chỉnh lý bản đồ địa chính tập trung tại 68 xã, phường, thị trấn trên địa bàn 5 đơn vị cấp huyện (bao gồm: 32 xã, phường thuộc TP. Thái Nguyên, 10 xã phường thuộc TP. Sông Công và 3 xã thuộc huyện Đồng Hỷ, 3 xã huyện Phú Lương, 20 xã huyện Phú Bình) với tổng diện tích chỉnh lý 47.535,47 ha.

- Đo đạc chỉnh lý bản đồ địa chính không tập trung tại các huyện Định Hóa, Đại Từ, Phú Lương, Đồng Hỷ, Phú Bình, Võ Nhai, TP Thái Nguyên và thị xã Phổ Yên với 106.309 thửa.

- Đo đạc, cắm mốc ranh giới phần đất các công ty nông, lâm nghiệp giữ lại tại 9 xã, thuộc 4 đơn vị cấp huyện: $3.618,7$ ha; đất bàn giao về địa phương tại 8 xã, thuộc 3 đơn vị cấp huyện: 4.008,02 ha.

\section{KẾT LUẦN}

- Tỉnh Thái Nguyên có vị trí địa lý thuận lợi trong việc mở rộng giao lưu kinh tế với các tỉnh, thành phố trong vùng, trong cả nước cũng như với nước ngoài trong thời kỳ hội nhập và phát triển kinh tế. Tổng diện tích tự nhiên toàn tỉnh năm 2019 là 352.664ha trong đó: Đất nông nghiệp: 303.555ha, chiếm 86,08\% diện tích tự nhiên; Đất phi nông nghiệp: 44445ha, chiếm 12,63\% diện tích tự nhiên; Đất chưa sử dụng: 4664 ha, chiếm $1,33 \%$ diện tích tự nhiên.

- Tính đến hết năm 2019 tỉnh Thái Nguyên đã thực hiện đo đạc lập bản đồ địa chính được 180/180 xã, phường, thị trấn thuộc 9 huyện, thành phố, thị xã với tổng diện tích là $340.945,7$ ha/352.664 ha, chiếm $96,7 \%$ tổng diện tích tự nhiên toàn tỉnh.

- Đo đạc thành lập bản đồ địa chính gắn với cấp GCNQSD đất và xây dựng cơ sở dữ liệu địa chính tại 28 xã, thị trấn thuộc 4 huyện Võ Nhai, Đồng Hỷ, Định Hoá, Đại Từ với tổng diện tích 21.291,0 ha;

\section{TÀI LIỆU THAM KHẢO}

1. Ministry of Natural Resources and Environment (2014). Circular No. 25/2014 / TTBTNMT dated May 19, 2014 on cadastral maps.

Department of Natural Resources and Environment of Thai Nguyen Province (2019).Land inventory report 2019, Thai Nguyen province.

2. Department of Natural Resources and Environment of Thai Nguyen Province (2019). Reporting results of cadastral map measurement, cadastral record preparation, cadastral database development ofThai Nguyen province.

3. People's Committee of Thai Nguyen Province (2018). Decision No. 980 / QD-UBND dated April 16, 2018 approving technical design - cost estimates. Building a system of cadastral records and cadastral database of Thai Nguyen province.

4. People's Committee of Thai Nguyen Province (2019). Statistical yearbook of Thai Nguyen Province. 


\section{Research situation of using land status and managing of surveying cadastral maps in Thai Nguyen province}

Tran Thi Thu Hien, Le Thi Thu, Dam Thi Thanh Thuy

\begin{tabular}{l} 
Article info \\
\hline Recieved: \\
11/7/2020 \\
Accepted: \\
12/8/2020 \\
\hline
\end{tabular}

Keywords:

Research; current status; land use; management; measurement; cadastral maps; Thai Nguyen.

\begin{abstract}
In recent years, Thai Nguyen province has a rapid urbanization rate, so the management of measurement and establishing cadastral maps to manage and use rationally, the most effective state management of land is absolutely necessary. Thai Nguyen cadastral map has been established over the past 30 years (from 1986 up to now) using traditional and digital technologies, so there is a difference in accuracy. The localities measured before 2000 with traditional technology, measured by theodolite, processed data, edited the map, calculated the area by manual method, so the map had limited quality with low accuracy, leading to difficulties in land management by modern information technology. From December 31, 2019, Thai Nguyen province has carried out the survey and cadastral mapping for 180/180 communes, wards and towns in 9 districts, cities, towns, the completed volume. Details are as follows: Volume of setting up cadastral grid is 979 points in Thai Nguyen city, Song Cong city, Dong Hy district, Dinh Hoa district, Vo Nhai district, Phu Luong district and Dai Tu district. The total area measured cadastral mapping 340,945.7 ha / 352,664 ha, accounting for $96.7 \%$ of the total natural area of the province.
\end{abstract}

